\title{
Improved genetic distance-based spatial deployment can effectively minimize inbreeding in seed orchard
}

\author{
Boning Yang ${ }^{1}$, Haihong Sun², Jiandong Qi ${ }^{3}$, Shihui Niu', Yousry A. El-Kassaby ${ }^{4}$ and Wei Li $i^{*}$
}

\begin{abstract}
Background: Inbreeding in seed orchards is expected to increase with the advancement of breeding cycles, which results in the delivery of crops with suboptimal genetic gain, reduced genetic diversity, and lower seed set. Here, a genetic distance-dependent method for clonal spatial deployment in seed orchards was developed and demonstrated, which reduced the inbreeding levels. The method's main evaluation parameter of inbreeding is the genetic distance among individuals and the deployment method used an improved adaptive parallel genetic algorithm (IAPGA) based on Python language. Using inbreeding-prone Chinese Mongolian pine breeding population material originating from a single natural population, the proposed method was compared to a traditional orchard design and a distance-based design; namely, complete randomized block (RCB) and optimum neighborhood (ONA) designs, respectively.

Results: With the advancement of selective breeding cycles, group separation among orchard related individuals is expected to increase. Based on the genetic distance among individuals, the IAPGA design was superior in significantly reducing the inbreeding level as compared to the two existing designs, confirming its suitability to advanced-generation orchards where relatedness among parents is common. In the $1 \mathrm{st}$, $2 \mathrm{nd}$, and mixed generations clonal deployment schemes, the IAPGA design produced lower inbreeding with $87.22 \%, 81.49 \%$, and $87.23 \%$ of RCB, and $92.78 \%, 91.30 \%$, and $91.67 \%$ of ONA designs, respectively.

Conclusions: The IAPGA clonal deployment proposed in this study has the obvious advantage of controlling inbreeding, and it is expected to be used in clonal deployment in seed orchards on a large-scale. Further studies are needed to focus on the actual states of pollen dispersal and mating in seed orchards, and more assumptions should be taken into account for the optimized deployment method.
\end{abstract}

Keywords: Seed orchard, Deployment, Inbreeding, Genetic distance, Clone, SSR

\section{Background}

Seed orchards bridge forest tree selective breeding activities and reforestation/afforestation practices, which rely on the production of genetically improved seed (ElKassaby 1992, El-Kassaby, 2000a, b). The term "seed orchard genetic efficiency" reflects the genetic superiority and diversity of orchard crops, which resulted from the selection and random mating of their parents (Adams

\footnotetext{
* Correspondence: bjfuliwei@bjfu.edu.cn

'Beijing Advanced Innovation Center for Tree Breeding by Molecular Design, National Engineering Laboratory for Forest Tree Breeding, College of Biological Sciences and Technology, Beijing Forestry University, Beijing 100083, China

Full list of author information is available at the end of the article
}

1983; El-Kassaby et al. 1984). The maximum genetic efficiency of seed orchards requires the fulfillment of several biological factors like synchrony reproductive phenology and output equality among their parental population members along with minimal levels of inbreeding and gene flow (Eriksson et al. 1973). However, seed orchard research clearly showed that these factors are hardly met and several seed crop management practices have been proposed (e.g., bloom-delay (Silen and Keane 1969) and supplemental mass pollination (Wakeley et al. 1966)), which successfully implemented to minimize these deviations from the ideal state and close to perfect population expectations (El-Kassaby and Ritland 1986a, 1986b; Fashler and El-Kassaby 1987; El-Kassaby and Davidson 
1990; El-Kassaby and Reynolds 1990; Reynolds and Elkassaby, 1990; El-Kassaby and Cook 1994; Song et al. 2018). While the implemented seed orchard management practices were effective in minimizing most of these biological deviations, minimal inbreeding is still strictly a function between the design of the orchard (i.e., the spatial arrangement among related individuals) and the degree of relatedness among the orchard parental population. Extensive studies have been conducted to assess the mating system and pollination dynamics in seed orchards (El-Kassaby and Ritland 1986a, 1986b; ElKassaby et al. 1988; El-Kassaby et al. 1989; El-Kassaby and Davidson 1991; Song et al. 2018); however, the extent of inbreeding is difficult to determine, as it is a function of the relatedness among the members of parental population. Inbreeding of seed orchards is expected to increase with the advancement of breeding cycles due to the selection and inclusion of related individuals in new orchards (El-Kassaby and Ritland 1996a, El-Kassaby et al., 2011 1996b). For example, inbreeding in the first generation (1st-Gen) clonal or seedling (i.e., open-pollinated (OP)) seed orchards is restricted to selfing (within trees and among ramets of the same clone) and sib-mating (among OP family members), respectively (El-Kassaby, 2000a, b). However, in upgraded (1.5-Gen) or advanced (2nd-Gen) generations and rolling-front orchards (Borralho et al. 1998), the level of inbreeding becomes more complex and is mainly determined by the pedigree of orchard population (e.g., as several individuals with various degree of relatedness are often selected and included), thus in addition to selfing, multiple inbreeding forms are expected (e.g., selfing, sibmating, parent-offspring, etc.) (El-Kassaby, 2000a, b).

Mating among relatives in seed orchards often leads to inbreeding depression, which results in the delivery of crops with suboptimal genetic gain, reduced genetic diversity, and lower seed yield (Griffin and Lindgren 1985; Woods and Heaman 1989; Williams and Savolainen 1996). Inbreeding depression mainly results from either selfing or correlated mating (Jain 1976; Ritland 1989; Keller and Waller 2002). Plant pollination dynamic research has indicated that the majority of mating occurred within a certain distance between individuals, thus it is necessary to highlight the importance of separating related individuals beyond the effective pollen dispersal distance (Levin and Kerster 1974; Adams and Birkes 1991; Li et al. 2019; Zhang et al. 2019). The concern over inbreeding build-up in seed orchard crops necessitated the development of orchard designs aimed at separating relatives (Giertych 1975). Multiple seed orchard designs were developed ranging from those utilizing systematic arrangement of parents placement (Hodge and White 1993; El-Kassaby 2003; El-Kassaby et al. 2007) to those relying on computer-based algorithms (Bell and Fletcher 1978). Additionally, innovative designs were developed to accommodate new arrangements such as linear deployment (Lindgren et al. 2009). Finally, more sophisticated computer-assisted designs suitable for advanced generation seed orchards became necessary to ensure separating related individuals. Such as the minimum inbreeding design (MI) which controls inbreeding levels by effectively optimizing the spatial distance between related individuals (i.e. the ramets of the same clone or half-siblings) in a deployment scheme (LstibůRek and El-kassaby 2010), and this design was optimized in subsequent studies for accommodate advanced generation seed orchards (Lstibůrek et al. 2015). Similar to MI, the randomized, replicated, staggered clonal-row design $\left(R^{2} S C R\right)$ focuses on the spatial distance between related parents (El-Kassaby et al. 2014); and the optimum neighborhood design (ONA) used a" trial-and-error" method to optimize orchard's arrangement and effective spatial deployment among adjacent clones (Chaloupková et al. 2016). Finally, the combination of ONA and MI design has proven to be effective in parental allocation even in irregular shape orchards making it suitable for modifying existing seed orchard (Chaloupková et al. 2019).

Mongolian pine or Hailar pine (Pinus sylvestris var. mongolica) is a geographical variety of Scots pine $(P$. sylvestris) (Zhu et al. 2006), which is one of the main afforestation species in northern China with suitable growth on barren soil due to its tolerance of cold and drought (Zhao et al. 2007; Wu et al. 2019). The genetic improvement of Mongolian pine started in China in the 1950s (Kang et al. 2004) and it is at the initial stage of second-generation breeding cycle. The Honghuaerji provenance, consisting of five natural stands, represents a main source of Mongolian pine breeding program in China. Additionally, the introduction trial was carried in three geographically distant areas (Cuohai, Tailai, and Yulin), which also contributed to the breeding material of the species. The breeding program proceeded with selection of the parental populations from these sources and the establishment of the 1st-Gen seed orchard and open-pollinated progeny test trials. It should be emphasized that selections for the 2nd-Gen seed orchard were made from these open-pollinated tests, highlighting the increased risk of inbreeding depression in these orchards as the pedigree of these selections were unknown ( $\mathrm{Ye}$ 1986; Mao et al. 1991; Zhang et al. 2012).

DNA markers can be effectively used to determine the genetic distance and estimate kinship among individuals as well as their inbreeding levels (Vaillancourt et al. 1998; Hardy 2003). The molecular marker-based genetic distance estimation among individuals have been used for pedigree reconstruction and paternity testing (Han et al. 2017; Huang et al. 2018), and it was also used for 
determining the spatial arrangement of an orchard population but only where the numbers of parents is limited (Yuan et al. 2016). Here, we used SSR markers to analyze the genetic distance among 224 clones of Mongolian pine 1st-, 1.5-, and 2nd-generation seed orchards. In turn, the estimated genetic distances were used to deploy parents (clones in this case) by an "improved adaptive parallel genetic algorithm" (IAPGA) program (Wang et al. 2018). The aim of the developed algorithm is to use the genetic distance among Mongolian pine clones as a driver for minimizing the effect of inbreeding depression through improved spatial clonal deployment.

\section{Materials and methods}

\section{Clonal source and genetic data collection}

A total of 224 Mongolian pine parents (clones) were used to populate three different seed orchard generations (1st-, 1.5- and 2nd-Gen). The 1st generation seed orchard parents were selected from five natural stands Honghuaerji (LZJD), Toudaoqiao (TDQ), Baogenyuan (BGY), Baritu (BA), and Honglinchang (HLC), each contributing $57,15,11,11$ and 14 parents, respectively. The 1.5 generation seed orchard parental population consisted of 28 superior trees selected from the 1st-Gen seed orchard of Yulin (YL1.5). The 2nd generation seed orchard parent clones were from Cuohai $(\mathrm{CH} 2)$, Tailai (TL2), and Yulin (YL2), with 34, 33, and 21 clones, respectively. Genomic DNA was extracted from needles of each individual using a modified CTAB method (Crowley et al. 2003). We used 11 pre-selected polymorphic simple sequence repeat (SSR) primers for PCR amplification from previous study (Fang et al. 2014). The PCR products were analyzed by capillary electrophoresis, and genotyping was performed in GenemarkerV2.2.0 (Hulce et al. 2011).

\section{Data analysis}

Fragments length information of all individuals were used for genetic parameters calculation using PowerMarkerV3.25 software (Liu et al. 2005) and pairwise genetic distance was calculated as follows:

$$
D=1-\frac{\sum_{r} S}{2 r}
$$

where $D$ is "shared allele distance" that ranges from 0 to $1, S$ is the number of shared alleles summed over all loci, and $r$ is the number of marker loci (Kirst et al. 2005).

Dendrograms based on pairwise genetic distance between individual clones were established by UPGMA (unweighted pair-group method using arithmetic averages) and viewed using MEGAV7.0.14 software (Kumar et al. 2016).

\section{Mathematical model and optimization program}

The deployment clones were divided into three groups: 1st- $(n=108), 2$ nd- $(n=88)$, and mixed-generation $(n=$ 224), which represent the parents of forward selection, backward selection and overlapping generations, respectively. The genetic distance of each group was used as the raw data for clonal deployment. The orchard configuration was assumed to be a rectangle grid with uniform landform. Minimizing the probability of inbreeding was based on maintaining maximum distance between clones with low values of genetic distance. Assuming the size of the deployment is $M \times N$, that is, the number of rows and columns is $M$ and $N$, respectively, and the serial number of the first and last deployment spots (assigned locations) on the orchard grid as 1 and $M \times N$, respectively (eq. (2)). The neighborhood of the deployment spots located at the boundary of the matrix is incomplete, so 0 was used as a filler in the simulated clonal deployment matrix, and set the genetic similarity between these zero-filled points and other points to 0 (ie, there is no inbreeding between each other) to facilitate the operation (eq. (2)).

$$
\left[\begin{array}{cccccc}
0 & 0 & 0 & \cdots & 0 & 0 \\
0 & 1 & 2 & \cdots & N & 0 \\
0 & N+1 & N+2 & \cdots & 2 N & 0 \\
\vdots & \vdots & \vdots & \ddots & \vdots & \vdots \\
0 & (M-1) \times N+1 & (M-1) \times N+2 & \cdots & M \times N & 0 \\
0 & 0 & 0 & \cdots & 0 & 0
\end{array}\right]
$$

$$
M, N \in Z^{+}
$$

where $M$ is the total number of rows in the deployment scheme; $N$ is the total number of columns in the deployment scheme.

For each $3 \times 3$ matrix, the 8 external spots (clones) surrounding a central deployment spot are considered as its pollen source. Suppose $x$ is any spot on the configuration grid. These 8 spots are divided into two groups: one is the adjacent position corresponding to the top, bottom, left, and right $(x-N, x+N, x-1$, and $x+1)$ and the other is the 4 diagonal position $(x-N-1, x-$ $N+1, x+N-1, x+N+1)$. We set the spatial distance of the directly adjacent and diagonal positions to 1 and $\sqrt{2}$, respectively. Since the clone at the diagonal position (i.e., farther away from the center) has less influence, thus we divide the genetic similarity (Eq. 6) by $\sqrt{2}$ to adjust the effect of distance when solving the influence of the four oblique positions. Therefore, we propose the following function to calculate inbreeding levels $f\left(x_{i}\right)$ :

$$
f\left(x_{i}\right)=\sum_{j} I\left(x_{i}, x_{j}\right)+\sum_{k} I\left(x_{i}, x_{k}\right) / \sqrt{2}
$$

where 


$$
\begin{gathered}
i=(1,2,3, \cdots, M \times N) \\
x_{i} \rightarrow i, x \in Z^{+} \\
j=\{i+1, i-1, i+N, i-N\} \\
k=\{i+N+1, i+N-1, i-N+1, i-N-1\}
\end{gathered}
$$

where $f$ is the inbreeding levels of each deployment spot, $x_{i}$ is the central deployment spots in $3 \times 3$ matrix, $x_{j}$ is the deployment spots parallel adjacent with $x_{i}, x_{k}$ is the deployment spots diagonally adjacent with $x_{i}, I$ is genetic similarity, which was calculated as:

$$
I\left(x_{i}, x_{j}\right)=1-D\left(x_{i}, x_{j}\right) \text { or } I\left(x_{i}, x_{k}\right)=1-D\left(x_{i}, x_{k}\right)
$$

where $D$ is the pairwise genetic distance. In order to minimize the total inbreeding levels of all seed orchard individuals, we further propose the following objective function:

$$
F_{\min }=\min F=\min \sum f=\min \sum_{i=1}^{M \times N} f\left(x_{i}\right)
$$

where $F$ is the sum of all clones' inbreeding levels at each deployment scheme, $F_{\min }$ is the minimum of $F, f$ is the inbreeding levels of each clone calculated by Eq. (4).

Clones are deployed using an improved adaptive parallel genetic algorithm (IAPGA) (Wang et al. 2018). Following the genetic algorithm, the first step is to reassemble the deployment populations into multiple subpopulations. Then the sub-populations are processed by three steps; namely, selection, crossover, and mutation in the genetic algorithm reaching the maximum-times through an iterative calculation process to form several deployment schemes. Finally, the genetic similarity of the clones at each deployment point relative to the surrounding 8 clones were calculated separately (Eq. 6), and the inbreeding level values of the clones at each deployment point were obtained (Eq. 4). The sum of the inbreeding level of the clones of all the configuration points on each deployment scheme was used as the basis for judging, and the results with the lowest inbreeding level were selected by Eq. (7).

\section{Evaluation of clonal deployment results}

In order to compare the different deployment methods on inbreeding level (using parameter $f$ in Eq. (4)), for demonstration purposes, we assumed that there are 4 ramets of each clone in the deployment results. The output of the IAPGA deployment algorithm is taken as a single block. Within each block, one ramet of each clone is included. Four replicas of the same block constituted a complete IAPGA deployment result. At the same time, the randomized complete block (RCB) design and optimum neighborhood (ONA) design are used to obtain the other two deployment results. The inbreeding level of each deployment spot under different designs was calculated, and the control of the spatial distance of individuals with close kinship is compared across the 3 different designs; then the inbreeding level of each deployment spot is calculated.

\section{Results}

The similarity of parents in the orchards increased with the advancement of breeding cycles

With the advancement of selective breeding cycles, group separation (Dendrogram) among seed orchard individuals is expected to increase. This is clearly demonstrated by the genetic distance between individuals in the three seed orchards (1st-, 1.5-, and 2ndgenerations) (Fig. 1). The results of dendrogram showed that in the 1st genetic resource $(n=108)$, the "BA12" clone is separated from the remaining 107 clones at a genetic distance of 0.308 , indicating that it has significant genetic differences with the other clones (Fig. 1a). The genetic separation of the genetic resource representing the $1.5-\mathrm{Gen}$ orchard $(n=28)$ is clearer than that of the 1st-Gen and the 28 clones are roughly divided into two groups at the genetic distance value of 0.2105 (Fig. 1b). Clones "SH1, SH65, and SH34" which originated from the same genetic source clustered in one group (blue in Fig. 2b), confirming their close genetic relatedness. The grouping of third genetic resource representing the 2nd-Gen orchard is the most striking among the three populations and it is divided into 6 groups at the genetic distance value of 0.1912 (Fig. 1c). Due to the complex relationship between individuals, the proportion of the population included in each group is also different. For example, there are 26 clones in group II (orange), including individuals from $\mathrm{CH} 2, \mathrm{TL} 2$, and YL2, with $30.77 \%$ (8), 53.85\% (14), and $15.38 \%$ (4), respectively (Fig. 1c). There are 15 clones in group V (purple), and the three groups represented 46.67\% (7), $40.00 \%$ (6), and $13.33 \%$ (2), respectively (Fig. 1c). In addition, there are 88 ramets in the 2nd-Gen orchard representing 86 parents (ortets), with ramets "YL1417 and YL1411", "CH3 and CH10" representing the same clone, respectively, which was most likely caused by mistaken records.

\section{IAPGA algorithm is effective in minimizing inbreeding in clonal orchards deployment}

The clonal deployment schemes by IAPGA design are depicted in squares, which represent the 3 seed orchards $(1$ st- $(12 \times 9)$, 2 nd- $(11 \times 8)$, and mixed- $(16 \times 14)$ generations, respectively) with square color patches, where each patch represents a clone planting position and patch colors reflecting different inbreeding levels (Fig. 2). The inbreeding level of the individuals at the edge is lower as they have fewer neighbors compared to 


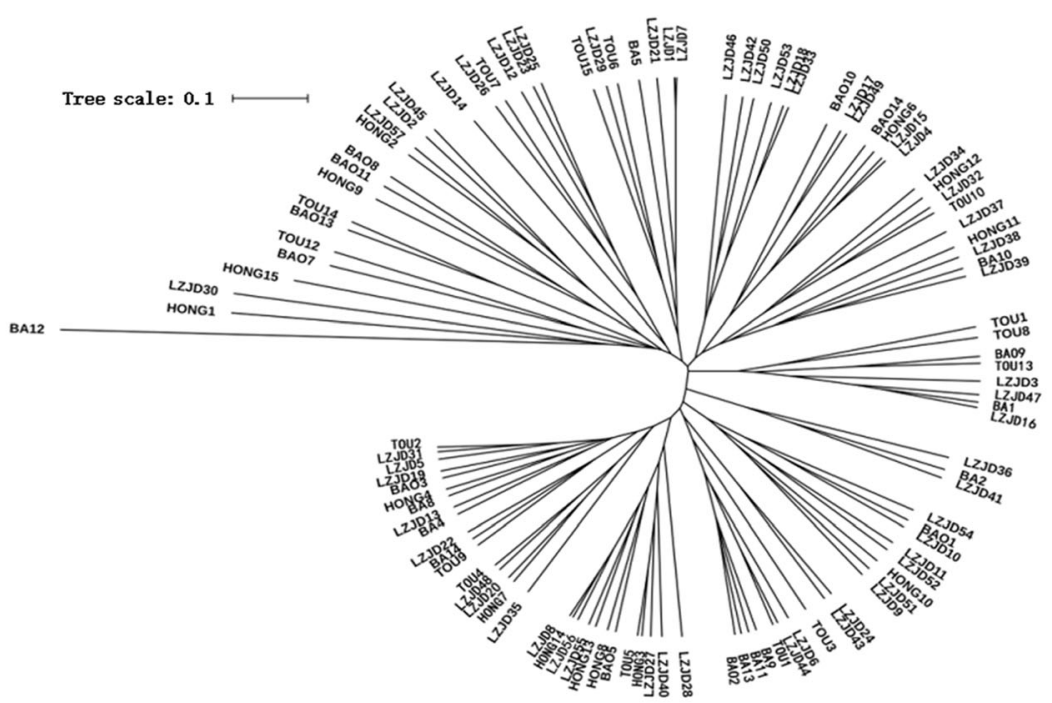

(a)

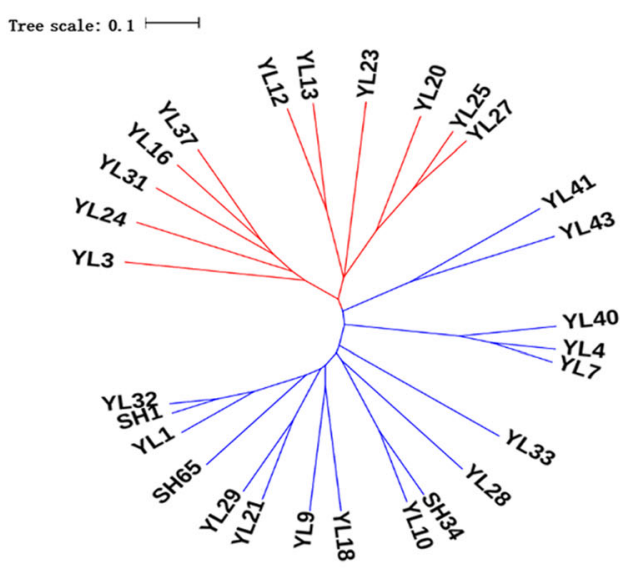

(b)

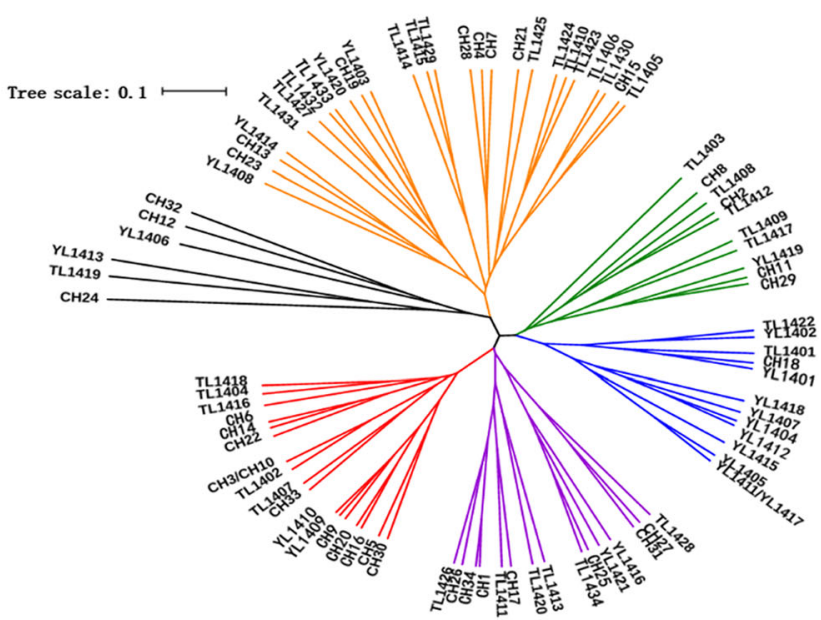

(c)

Fig. 1 The average un-weighted pair group method (UPGMA) dendrograms of the relationship among trees of the three Mongolian pine genetic sources present in three seed orchards (1st- (a), 1.5- (b), and 2nd- (c) generations) according to pairwise genetic distance

those in the center. The inbreeding levels of each planting position in each deployment scheme is under 5. Clones with the lowest and highest inbreeding levels across the 3 generation orchards were associated with specific parents ((1st-: YL1420 and CH10 with inbreeding levels of 1.51 and 4.38, respectively), (mixed-: TL1427 and BAO30 with inbreeding levels of 1.51 and 4.55, respectively), and (2nd-: LZJD38 and HONG112 with inbreeding levels of 1.42 and 4.26, respectively)) (Fig. 2). With the same configuration algorithm parameters, the deployment results gradually show non-uniform phenomenon with the increase of the population size, with noticeable lower inbreeding levels in the upper half of the mixed-Gen orchard as compared to the corresponding lower half.

\section{IAPGA clonal deployment has obvious advantages over} the existing designs

For seed orchards' design comparison, clones of three Mongolian pine populations were deployed using: 1) the genetic distance-based IAPGA design, 2) randomized complete block design, and 3) optimum neighborhood (ONA) design. The comparison clearly shows that the IAPGA design can significantly reduce the total inbreeding levels in the seed orchard compared to the traditional RCB and ONA designs (Table 1). The IAPGA design produced overall inbreeding levels (The sum of the inbreeding levels of all deployment points) of $1565.760,1221.900$, and 3272.830 with averages of 3.624 , 3.471 , and 3.652 for the 1st-, 2nd-, and mixedgeneration seed orchards, respectively (Table 1). The 


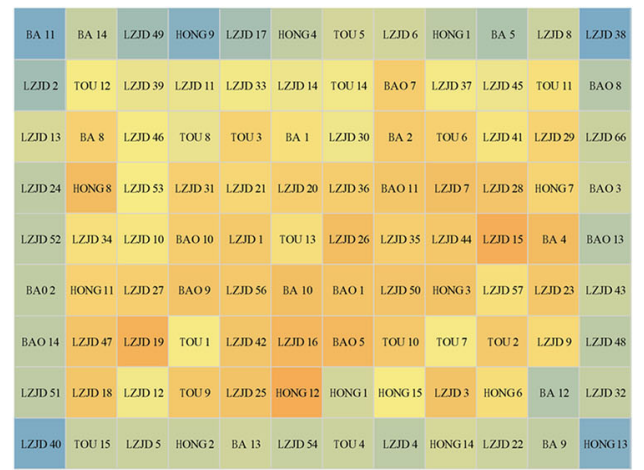

(a)

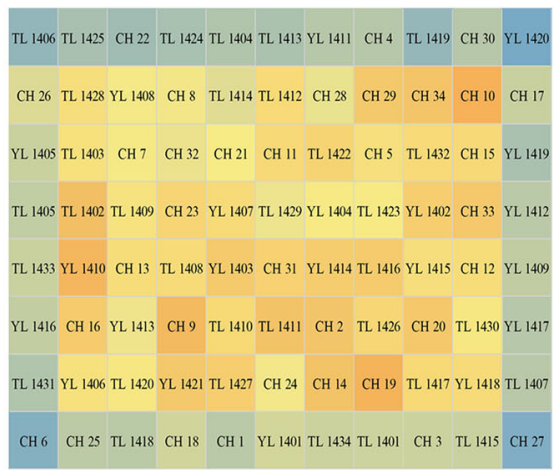

(b)

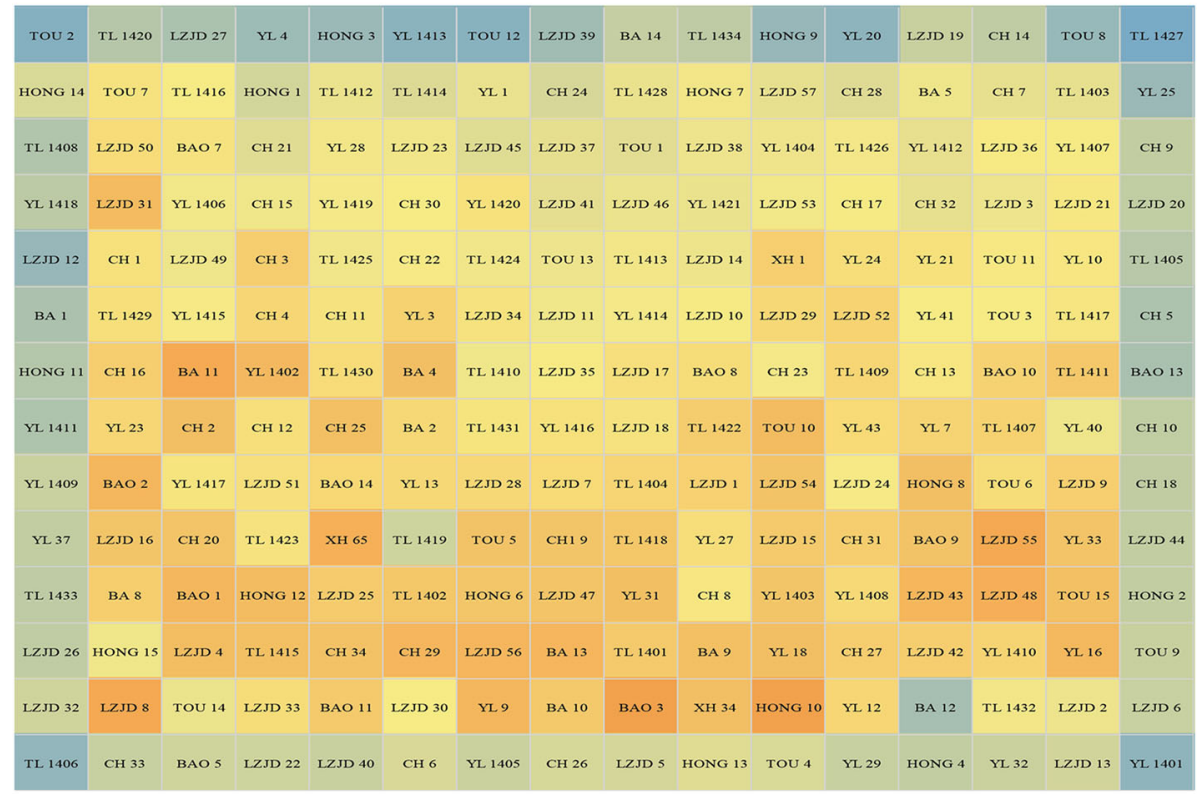

(c)

Inbreeding level:

Fig. 2 The clonal deployment scheme of three-generation deployment groups. Note: where (a), (b), (c) is the clonal deployment scheme of 1st-, 2nd-, and mixed-generation seed orchard, respectively. Different background colors represent different degrees of inbreeding levels

Table 1 Descriptive statistics of inbreeding level under the genetic distance-based IAPGA, RCB, and ONA designs for first (1st), second (2nd), and mixed generation seed orchards

\begin{tabular}{|c|c|c|c|c|c|c|c|c|c|}
\hline \multirow[t]{2}{*}{ Statistics } & \multicolumn{3}{|c|}{ 1st gen $\mathrm{SO}$} & \multicolumn{3}{|c|}{ 2nd gen SO } & \multicolumn{3}{|c|}{ Mixed gen SO } \\
\hline & IAPGA & $\mathrm{RCB}$ & ONA & IAPGA & RCB & ONA & IAPGA & $\mathrm{RCB}$ & ONA \\
\hline Mean & 3.624 & 4.155 & 3.907 & 3.471 & 4.260 & 3.802 & 3.652 & 4.187 & 3.984 \\
\hline Standard deviation (SD) & 0.640 & 0.764 & 0.699 & 0.620 & 0.761 & 0.682 & 0.586 & 0.722 & 0.631 \\
\hline Variance & 0.409 & 0.584 & 0.488 & 0.384 & 0.580 & 0.465 & 0.343 & 0.521 & 0.398 \\
\hline Minimal value & 1.512 & 1.067 & 1.699 & 1.434 & 1.584 & 1.643 & 1.510 & 1.081 & 1.564 \\
\hline Maximum value & 4.801 & 5.575 & 5.001 & 4.821 & 5.316 & 4.966 & 4.949 & 5.702 & 5.464 \\
\hline Sum & 1565.760 & 1795.040 & 1687.689 & 1221.900 & 1499.350 & 1338.368 & 3272.830 & 3751.960 & 3570.000 \\
\hline Coefficient of variation (CV) & 0.1765 & 0.1839 & 0.1789 & 0.1786 & 0.1787 & 0.1793 & 0.1604 & 0.1723 & 0.1583 \\
\hline Relative percentage (\%) & - & 87.22 & 92.78 & - & 81.49 & 91.30 & - & 87.23 & 91.67 \\
\hline
\end{tabular}


RCB design yielded 1795.040, 1499.350, and 3751.960 with averages of $4.155,4.260$, and 4.187 for the 1st-, 2nd-, and mixed-generation seed orchards, respectively (Table 1). Finally, the ONA design produced overall inbreeding levels of $1687.689,1338.368$, and 3570.000 with averages of $3.907,3.802$, and 3.984 for the 1st-, 2nd-, and mixed-generation seed orchards, respectively (Table 1). Across the three clonal deployments, the RCB design scheme produced the highest overall inbreeding level followed by the ONA design, while the IAPGA design was the lowest (Table 1). For the IAPGA design, the inbreeding levels in the 1st-, 2nd-, and mixed-Gen orchards were $87.22 \%, 81.49 \%$, and $87.23 \%$ for the RCB design, respectively, while it resulted in $92.78 \%, 91.30 \%$, and $91.67 \%$ for the ONA design, respectively. The coefficient of variation (CV) indicates the change of inbreeding levels of the deployment spots in each population. In the 1st- and mixed-generation seed orchards the inbreeding level CV of RCB design was the highest among the three deployment designs; while no significant difference was observed in 2nd-Gen.

\section{IAPGA design inbreeding level is relatively stable across deployment spots}

The improved deployment optimizes and controls the overall inbreeding levels to a low degree and avoids the occurrence of extreme inbreeding level values at the deployment spots (Fig. 3). The IAPGA deployment results of the 1st- and 2nd-Gen seed orchard populations, produced inbreeding probability extreme values at a much lower level than the other two deployments (i.e., $\mathrm{RCB}$ and ONA designs). In the mixed-Gen deployment population, the overall layout of the ONA and the RCB designs was similar; however, the overall inbreeding levels of the optimized IAPGA deployment is lower, yet few extreme inbreeding level spots appeared in the layout (Fig. 3).

The distribution and pattern of clonal inbreeding level range substantially varied among the three deployment schemes (IAPGA, RCB, and ONA designs) (Table 2). It is noteworthy to highlight the close-to-normal distribution of the inbreeding level value ranges across the IAPGA design as opposed to the steady increase of inbreeding values in both the RCB and ONA (Table 2). Additionally, whichever deployment methods were used, the mixed-Gen seed orchard produced a higher inbreeding levels as compared to the 1st- and 2nd-Gen orchards (Table 2). Generally, there were no spots with inbreeding value less than 1 in the three deployment methods. The IAPGA deployment was the only design with no inbreeding levels more than 5 while these values existed in the RCB $(44,32$, and 75 for the 1st-,2nd-, and mixedGen seed orchards, respectively) and ONA (1, 0, and 10 for the 1st-, 2nd-, and mixed-Gen seed orchards, respectively) designs (Table 2). Finally, it is worth noting that the IAPGA deployment results produced more inbreeding level clones within the 0-4 range compared to the RCB and ONA designs (Table 2).

\section{Discussion \\ Genetic relationship among individuals in seed orchards of different generations}

Mating among relatives in seed orchard populations often leads to reduced seed yield and performance of inbreeding seedlings which persists throughout the tree life (Woods and Heaman 1989; Woods et al. 2002; Wang et al. 2004; Stoehr et al. 2015). Under the known genetic control of seed germination (Chaisurisri et al. 1992; ElKassaby et al. 1992; El-Kassaby et al. 2008) coupled with the commonly used non-competitive practices of seedling production (El-Kassaby and Thomson 1995; ElKassaby, 2000a, b), this inbreeding passes undetected and thus it cannot be ignored and must be managed in seed orchards. Absolute control of inbreeding in seed orchards through deliberate controlled pollination to avoid mating among relatives is exceedingly prohibitive and generally is impractical on operational level. The genealogical relationship (i.e., pairwise kinship) among seed orchard parents (clones) can be discerned with molecular markers (El-Kassaby et al. 2011). In the present study, the 1st-, 1.5-, and 2nd-Gen seed orchards produced drastically different patterns of phylogenetic tree (Fig. 1). The 1st-Gen orchard produced an uniform distribution indicating that none of the initial parent selection was related in spite of their original single source (Honghuaerji provenance) (Fig. 1). On the other hand, the 1.5- and 2nd-Gen orchards produced 2 and 6 groups in their respective phylogenetic trees, respectively, indicating build-up of co-ancestry (Fig. 1). The observed genetic clustering in the 1.5- and 2nd-Gen orchards is the result of selection of several individuals with common parentage, a situation frequently encountered during selection after progeny testing as top rank performing families often contribute more selected individuals than their lower-performing counterparts. The selection of several individuals from few top-ranking families for their incorporation in seed orchards leads to reduced genetic diversity and build-up of co-ancestry, a situation requiring innovative seed orchard designs for inbreeding avoidance (El-Kassaby 1991; El-Kassaby 1995).

\section{Genetic distance-based clonal deployment}

Mating in seed orchard populations is a complex biological function and is influenced by many factors, including spatial arrangements of parents (ramets), their genetic relationship (genetic distance in the present study), and reproductive output and phenology. In the present study, we introduced the genetic distance-based 


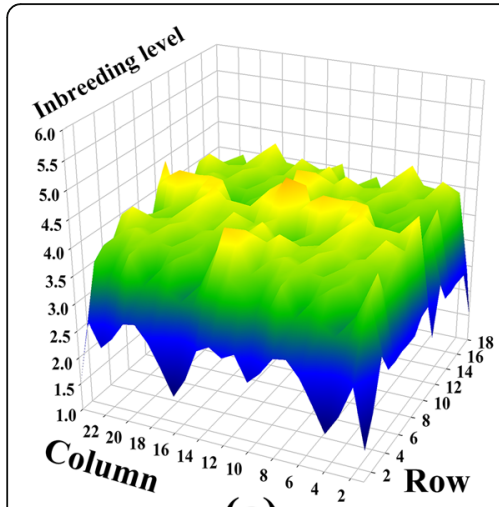

(a)

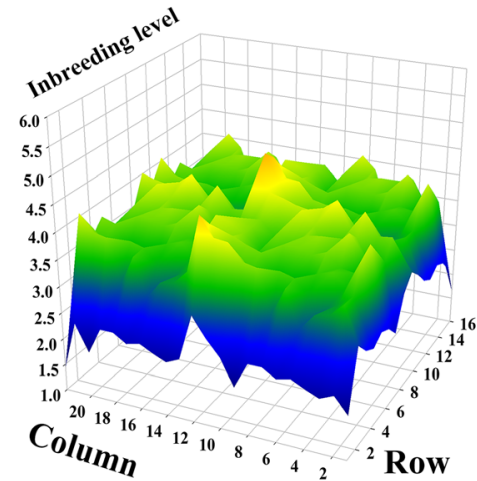

(d)

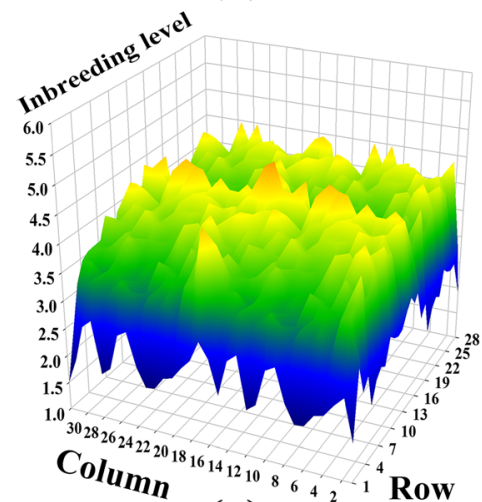

(g)

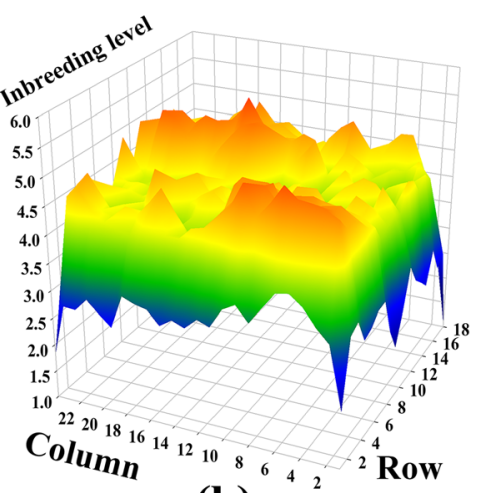

(b)

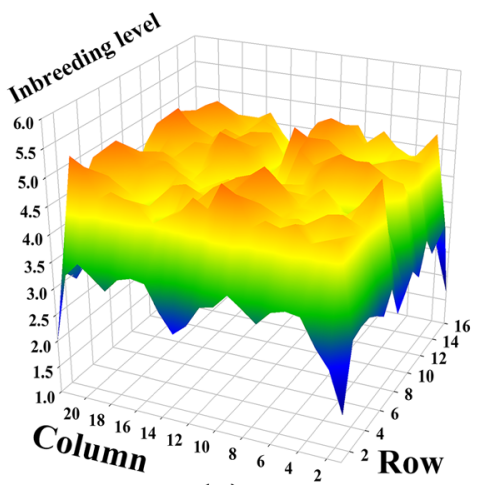

(e)

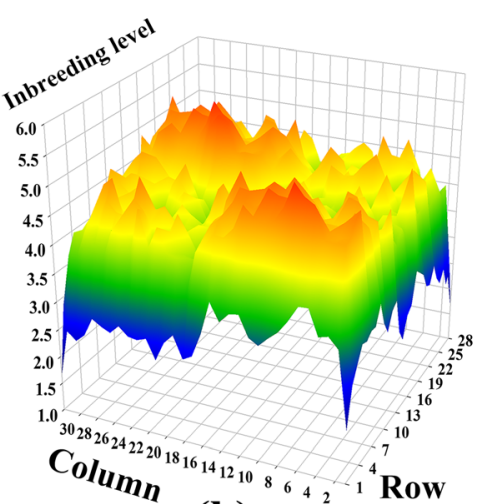

(h)

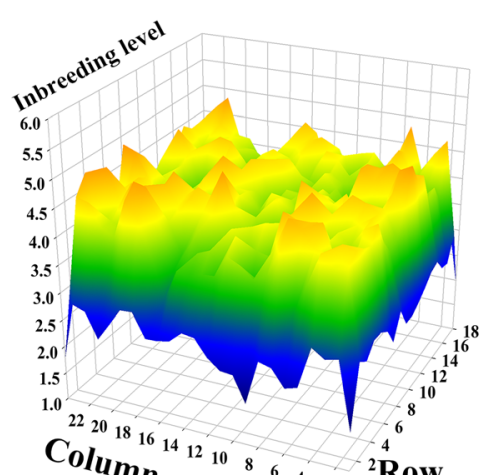

(c)

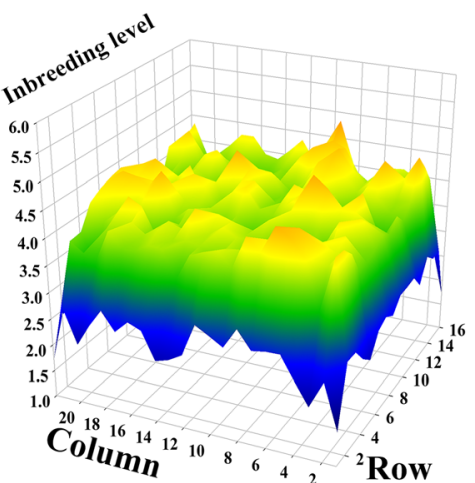

(f)

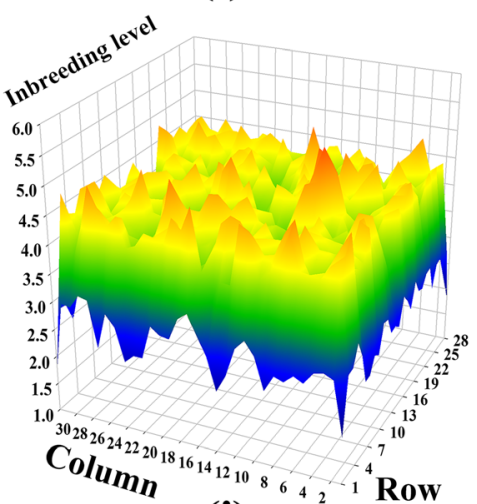

(i)

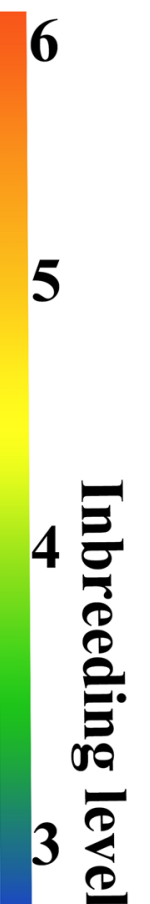

Fig. 3 Inbreeding level Comparison among the improved adaptive parallel genetic algorithm (IAPGA), randomized complete block (RCB), and optimum neighborhood (ONA) seed orchard designs (1st Gen IAPGA (a), RCB (b), ONA (c); 2nd Gen IAPGA (d), RCB (e),ONA (f); mixed Gen IAPGA (g), (RCB (h), ONA (i))

Table 2 Inbreeding level for the IAPGA, complete randomized block (RCB), and optimum neighborhood (ONA) design for the 1st-, 2nd- mixed- Gen seed orchards

\begin{tabular}{|c|c|c|c|c|c|c|c|c|c|}
\hline \multirow{2}{*}{$\begin{array}{l}\text { Inbreeding } \\
\text { level range }\end{array}$} & \multicolumn{3}{|l|}{ IAPGA } & \multicolumn{3}{|l|}{$\mathrm{RCB}$} & \multicolumn{3}{|l|}{ ONA } \\
\hline & 1st Gen & 2nd Gen & mixed Gen & 1st Gen & 2nd Gen & mixed Gen & 1st Gen & 2nd Gen & mixed Gen \\
\hline $1-2$ & 6 & 6 & 16 & 4 & 3 & 6 & 5 & 5 & 4 \\
\hline $2-3$ & 82 & 68 & 104 & 51 & 38 & 82 & 66 & 64 & 106 \\
\hline $3-4$ & 190 & 230 & 502 & 66 & 39 & 177 & 105 & 105 & 228 \\
\hline $4-5$ & 154 & 48 & 274 & 267 & 240 & 556 & 255 & 178 & 548 \\
\hline$>5$ & 0 & 0 & 0 & 44 & 32 & 75 & 1 & 0 & 10 \\
\hline
\end{tabular}


IAPGA algorithm for designing seed orchards and therefore the genetic distance among individuals is the only constraint influencing clonal configuration on the seed orchard grids. Unlike existing seed orchard designs, where separation among related clones is implemented through enforcing separation zones among clonal ramets or among related clones and their ramets (El-Kassaby et al. 2014), the collective use of genetic relationship among parents has not been considered. The feasibility of using the genetic relatedness among individuals has been previously attempted in designing seed orchards (LstibůRek and Elkassaby 2010; Lstibůrek et al. 2015; Chaloupková et al. 2016; Chaloupková et al. 2019) and ex-situ conservation plantations (Fernández and González-Martínez 2009). The basic principle of IAPGA design proposed in this study is the same as that of ONA design, that is, to match each clone in the configuration scheme with the optimum neighborhood, so as to minimize the mating probability between related parents. The difference is that we combine genetic distance with the method of matching the optimum neighborhood, and use this method to further reduce the inbreeding, not only including self-mating. Moreover, the proposed genetic distance-based IAPGA algorithm with its use of $3 \times 3$ neighborhood matrix (i.e., eight spots around each center deployment spot) and correlating the genetic distance to clonal deployment is exceedingly efficient and it is also not restricted to orchard size or configuration.

\section{Advantages of the genetic distance-based IAPGA design}

In the present study, we used pairwise genetic distance as the original data, and the inbreeding level value $(f)$ as the evaluation parameter to analyze and compare the IAPGA designs with the "traditional" randomized complete block (RCB) design and new distance-based optimum neighborhood (ONA) design. For the 1st-, 2nd-, and mixed-Gen seed orchards, the inbreeding level value of IAPGA is approximately $87.22 \%, 81.49 \%$, and $87.23 \%$ of the randomized complete block design, while $92.78 \%, 91.30 \%$, and $91.67 \%$ of the ONA design, respectively (Table 1), indicating that the IAPGA design (include the inbreeding level values for the three orchards here) is able to effectively reduce the inbreeding level of the studied deployments. At the same time, we also noticed that the inbreeding levels of RCB design were always higher than ONA design in different generation seed orchards. For the 1st-, 2nd-, and mixed-Gen seed orchards, the sum of inbreeding values is 1795.040 , 1499.350, and 3751.960 for RCB design, and 1687.689, 1338.368 , and 3570.000 for ONA design, indicating that the deployment of ramets in different blocks had a certain positive effect on inbreeding reduction which in this case is only limited to selfing (Table 1). Overall, the clonal deployment layout of the IAPGA design produced lower inbreeding levels than the two existing (RCB and ONA) designs as there were no inbreeding levels lower than 1 or higher than 5 present in the IAPGA, while extreme inbreeding levels appeared in the traditional designs (Table 2).

Finally, it should be pointed out that in the present study, we used 8 positions around each central spot (clone) and assumed that they will constitute the main pollen source. However, in practice pollen, dispersal distance should differ based on wind direction and velocity as well as parental reproductive phenology and output; factors could cause some deviation between the assumed conditions for the developed method and those of actual situation. Additionally, we assumed the orchard's site is on flat terrain, an ideal situation that many seed orchards could deviate from, thus influencing our pollen dispersal assumptions. Here, we combined the pairwise genetic distance between parents with the Euclidean distance on the deployment matrix to evaluate the inbreeding level, which is a preliminary attempt. In the case where the progenies can be collected, gene flow (based on paternity analysis) is expected to be an important parameter evaluating inbreeding level and provides more references for seed orchard deployment (Dow et al. 1998; Ishihama et al. 2005; Moriguchi et al. 2005).

\section{Conclusion}

Here, we presented a genetic distance-dependent method for clonal deployment in a seed orchard. The method relies on optimizing the genetic relationship among individuals as the sole parameter in clonal deployment and aims to reduce the risk of inbreeding depression of seed orchard. The proposed method (IAPGA design) was compared to two existing designs (complete randomized block and optimum neighborhood designs) and the results showed IAPGA design superiority in significantly reducing the inbreeding level and demonstrated its potential suitability to advancedgeneration seed orchards where relatedness among parents is common.

\section{Abbreviations \\ IAPGA: Improved adaptive parallel genetic algorithm; ONA: Optimum neighborhood design; RCB: Randomized complete block design}

\section{Authors' contributions}

YB drew the figures and drafted the manuscript, SH collected data and samples in the field, QJ and NS helped to improve the design program, LW and YAE modified the manuscript, and all authors contributed to the writing of the manuscript. All authors read and approved the final manuscript.

\section{Funding}

This work was supported by grants from The Fundamental Research Funds for the Central Universities (2015-02), and the National Natural Science Foundation of China (Nos. 31770713, 31860221). 


\section{Availability of data and materials}

The datasets used and/or analyzed during the current study are available from the corresponding author upon reasonable request.

\section{Ethics approval and consent to participate}

Not applicable.

\section{Consent for publication}

Not applicable.

\section{Competing interests}

The authors declare that they have no competing interests.

\section{Author details}

${ }^{1}$ Beijing Advanced Innovation Center for Tree Breeding by Molecular Design, National Engineering Laboratory for Forest Tree Breeding, College of Biological Sciences and Technology, Beijing Forestry University, Beijing 100083, China. ${ }^{2}$ Liaoning Research Institute of Sandy Land Control and Utilization, Xihe District, Fuxin City 123000, Liaoning Province, China. ${ }^{3}$ College of Information Science and Technology, Beijing Forestry University, Beijing 100083, China. ${ }^{4}$ Department of Forest and Conservation Sciences, Faculty of Forestry, The University of British Columbia, 2424 Main Mall, Vancouver, British Columbia V6T 1Z4, Canada.

Received: 22 September 2019 Accepted: 3 February 2020

Published online: 13 February 2020

\section{References}

Adams W (1983) Application of isozymes in tree breeding. In: Tanksley SD, Orton TJ (eds) Developments in plant genetics and breeding. Elsevier, Amsterdam, pp 381-400

Adams W, Birkes DS (1991) Estimating mating patterns in forest tree populations. In: Hattemer HH, Fineschi S (eds) Biochemical markers in the population genetics of forest trees. Academic Publishing, The Hague, pp 157-172

Bell GD, Fletcher AM (1978) Computer organised orchard layouts (COOL) based on the permutated neighbourhood design concept. Silv Genet 27:223-225

Borralho NMG, Dutkowski GW (1998) Comparison of rolling front and discrete generation breeding strategies for trees. Can J For Res 28:987-993

Chaisurisri K, Edwards D, El-Kassaby YA (1992) Genetic control of seed size and germination in Sitka spruce. Silv Genet 41:348-355

Chaloupková K, Stejskal J, El-Kassaby YA, Frampton J, Lstibůrek M (2019) Current advances in seed orchard layouts: two case studies in conifers. Forests 10:93

Chaloupková K, Stejskal J, El-Kassaby YA, Lstibůrek M (2016) Optimum neighborhood seed orchard design. Tree Genet Genomes 12:105. https://doi. org/10.1007/s11295-016-1067-y

Crowley TM, Muralitharan MS, Stevenson TW (2003) Isolating conifer DNA: a superior polysaccharide elimination method. Plant Mol Biol Rep 21:97-97

Dow BD, Ashley MV (1998) High levels of gene flow in bur oak revealed by paternity analysis using microsatellites. J Hered 89:62-70

El-Kassaby YA (1991) Genetic variation within and among conifer populations: review and evaluation of methods. In: Fineschi S, Malvolti ME, Cannata F, Hattemer $\mathrm{HH}$ (eds) Biochemical markers in the population genetics of forest trees. SPB Academic Publishing bv, The Haque, pp 61-76

El-Kassaby YA (1992) Domestication and genetic diversity-should we be concerned? Forest Chron 68:687-700

El-Kassaby YA (1995) Evaluation of the tree-improvement delivery system: factors affecting genetic potential. Tree Physiol 15:545-550

El-Kassaby YA (2000a) Effect of forest tree domestication on gene pools. In: Young A, Boshier D, Boyle T (eds) Forest conservation genetics: principles and practice. CSIRO Publishing-CABI Publishing, Canberra, pp 197-213

El-Kassaby YA (2000b) Representation of Douglas-fir and western hemlock families in seedling crops as affected by seed biology and nursery crop management practices. For Genet 7:305-316

El-Kassaby YA (2003) Clonal-row vs. random seed orchard designs: mating pattern and seed yield of western hemlock (Tsuga heterophylla (Raf.) Sarg.). For Gen 10:121-127

El-Kassaby YA, Amk F, Sziklai O (1984) Reproductive phenology and its impact on genetically improved seed production in a Douglas-fir seed orchard. Silv Genet 33:120-125
El-Kassaby YA, Cappa EP, Liewlaksaneeyanawin C, Klápště J, Lstibůrek M (2011) Breeding without breeding: is a complete pedigree necessary for efficient breeding? PLoS One 6:e25737

El-Kassaby YA, Cook C (1994) Female reproductive energy and reproductive success in a Douglas-fir seed orchard and its impact on genetic diversity. Silv Genet 43:243-245

El-Kassaby YA, Davidson R (1990) Impact of crop management practices on the seed crop genetic quality in a Douglas-fir seed orchard. Silv Genet 39:230-237

El-Kassaby YA, Davidson R (1991) Impact of pollination environment manipulation on the apparent outcrossing rate in a Douglas-fir seed orchard. Heredity 66:55-59

El-Kassaby YA, Edwards DGW, Taylor DW (1992) Genetic control of germination parameters in Douglas-fir and its importance for domestication. Silv Genet 41:48-54

El-Kassaby YA, Fayed M, Klápště J, Lstibůrek M (2014) Randomized, replicated, staggered clonal-row (R 2 SCR) seed orchard design. Tree Genet Genom 10:555-563

El-Kassaby YA, Moss I, Kolotelo D, Stoehr M (2008) Seed germination: mathematical representation and parameters extraction. For Sci 54:220-227

El-Kassaby YA, Reynolds S (1990) Reproductive phenology, parental balance, and supplemental mass pollination in a Sitka-spruce seed-orchard. For Ecol Manag 31:45-54

El-Kassaby YA, Ritland K (1986a) Low levels of pollen contamination in a Douglasfir seed orchard. Silv Genet 35:5-6

El-Kassaby YA, Ritland K (1986b) The relation of outcrossing and contamination to reproductive phenology and supplemental mass pollination in a Douglasfir seed orchard. Silv Genet 35:240-244

El-Kassaby YA, Ritland K (1996a) Genetic variation in low elevation Douglasfir of British Columbia and its relevance to gene conservation. Biodivers Conserv 5:779-794

El-Kassaby YA, Ritland K (1996b) Impact of selection and breeding on the genetic diversity in Douglas-fir. Biodivers Conserv 5:795-813

El-Kassaby YA, Ritland K, Fashler A, Devitt WJB (1988) The role of reproductive phenology upon the mating system of a Douglas-fir seed orchard. Silv Genet 37:76-82

El-Kassaby YA, Rudin D, Yazdani R (1989) Levels of outcrossing and contamination in two scots pine seed orchards in northern Sweden. Scand J For Res 4:41-49

El-Kassaby YA, Stoehr MU, Reid D, Walsh CG, Lee TE (2007) Clonal-row versus random seed orchard designs: interior spruce mating system evaluation. Can J For Res 37:690-696

El-Kassaby YA, Thomson AJ (1995) Effect of seed biology and common seedling nursery production practices on parental contribution rank and relative performance. For Sci 42:228-235

Eriksson G, Lindgren D, Jonsson A (1973) Flowering in a clone trial of Picea abies karst. Technical Report, Stockholm

Fang P, Niu SH, Yuan HW, Li ZX, Zhang YC, Yuan L, Li W (2014) Development and characterization of 25 EST-SSR markers in Pinus sylvestris var. mongolica (Pinaceae). App. Plant Sci 2:1

Fashler A, El-Kassaby Y (1987) The effect of water spray cooling treatment on reproductive phenology in a Douglas-fir seed orchard. Silv Genet 36:245-249

Fernández J, González-Martínez SC (2009) Allocating individuals to avoid inbreeding in ex situ conservation plantations: so far, so good. Conserv Genet 10:45-57

Giertych M (1975) Seed orchard designs. In: Faulkner R (ed) Seed orchards. Forestry Commission Bulletin, London, pp 25-37

Griffin A, Lindgren D (1985) Effect of inbreeding on production of filled seed in Pinus radiata-experimental results and a model of gene action. Theor Appl Genet 71:334-343

Han Z, Gao P, Geng X, Du K, Kang X (2017) Identification of the male parent of superior half-sib Populus tomentosa individuals based on SSR markers. Mol Breeding 37:155

Hardy OJ (2003) Estimation of pairwise relatedness between individuals and characterization of isolation-by-distance processes using dominant genetic markers. Mol Ecol 12:1577-1588

Hodge GR, White TL (1993) Advanced-generation wind-pollinated seed orchard design. New For 7:213-236

Huang LS, Song JY, Sun YQ, Gao Q, Jiao SQ, Zhou SS, Jin YQ, Yang XL, Zhu رلـ Gao FL, El-Kassaby YA, Mao JF (2018) Pollination dynamics in a Platycladus orientalis seed orchard as revealed by partial pedigree reconstruction. Can J For Res 48:952-957 
Hulce D, Li X, Snyderleiby T, Johathan Liu CS (2011) GeneMarker ${ }^{\oplus}$ genotyping software: tools to increase the statistical power of DNA fragment analysis. J Biomol Tech 22(Suppl):S35

Ishihama F, Ueno S, Tsumura Y, Washitani I (2005) Gene flow and inbreeding depression inferred from fine-scale genetic structure in an endangered heterostylous perennial, Primula sieboldii. Mol Ecol 14:983-990

Jain S (1976) The evolution of inbreeding in plants. Annu Rev Ecol Syst 7:469-495

Kang H, Zhu J, Li Z, Xu M (2004) Natural distribution of Pinus sylvestris var. mongolica on sandy land and its cultivation as an exotic species. Chinese J Ecol 23:134-139 (in Chinese)

Keller LF, Waller DM (2002) Inbreeding effects in wild populations. Trend Ecol Evol 17:230-241

Kirst M, Cordeiro CM, Rezende GD, Grattapaglia D (2005) Power of microsatellite markers for fingerprinting and parentage analysis in Eucalyptus grandis breeding populations. J Hered 96:161-166

Kumar S, Stecher G, Tamura K (2016) MEGA7: molecular evolutionary genetics analysis version 7.0 for bigger datasets. Mol Biol Evol 33:1870-1874

Levin DA, Kerster HW (1974) Gene flow in seed plants. Evol Biol 7:138-220

Li X, Farooqi TJA, Jiang C, Liu S, Sun OJ (2019) Spatiotemporal variations in productivity and water use efficiency across a temperate forest landscape of Northeast China. For Ecosyst 6:22. https://doi.org/10.1186/ s40663-019-0179-x

Lindgren D, Danusevicius D, Rosvall O (2009) Unequal deployment of clones to seed orchards by considering genetic gain, relatedness and gene diversity. Forestry 82:17-28

Liu K, Muse SV (2005) PowerMarker: an integrated analysis environment for genetic marker analysis. Bioinformatics 21:2128-2129

Lstibưrek M, Elkassaby YA (2010) Minimum-inbreeding seed orchard design. For Sci 56:603-608

Lstibůrek M, Stejskal J, Misevicius A, Korecký J, El-Kassaby YA (2015) Expansion of the minimum-inbreeding seed orchard design to operational scale. Tree Genet Genome 11:1-8

Mao YQ, Zhang JL, Liu L, Wang FS, Zhang HP, Yuan LD (1991) Determination of primary seed garden generation and early gain of Pinus sylvestris var. mongolica. Protection for Sci Technol, pp 18-24 (in Chinese)

Moriguchi Y, Tani N, Itoo S, Kanehira F, Tanaka K, Yomogida H, Taira HTsumura Y (2005) Gene flow and mating system in five Cryptomeria japonica D. Don seed orchards as revealed by analysis of microsatellite markers. Tree Genet Genome 1:174-183

Reynolds S, Elkassaby YA (1990) Parental balance in Douglas-fir seed orchardscone crop vs. seed crop. Silv Genet 39:40-42

Ritland K (1989) Correlated matings in the partial selfer Mimulus guttatus. Evolution 43:848-859

Silen RR, Keane G (1969) Cooling a Douglas-fir seed orchard to avoid pollen contamination. USDA Forest Service, Pacific Northwest Forest and Range Experiment Station, Portland, Oregon

Song J, Ratcliffe B, Kess T, Lai BS, Korecký J, El-Kassaby YA (2018) Temporal quantification of mating system parameters in a coastal Douglas-fir seed orchard under manipulated pollination environment. Sci Rep 8:11593

Stoehr M, Ott P, Woods J (2015) Inbreeding in mid-rotation coastal Douglas-fir: implications for breeding. Ann For Sci 72:195-204

Vaillancourt RE, Skabo S, Gore PL (1998) Fingerprinting for quality control in breeding and deployment. Aust Forest 61:207-210

Wakeley PC, Wells OO, Campbell TE (1966) Mass production of shortleaf $\times$ slash pine hybrids by pollinating unbagged female flowers. Joint proceedings of the second genetics workshop of the Society of American Foresters and the seventh Lake states Forest tree improvement conference. Res pap NC-6. Department of Agriculture, Forest Service, north central Forest Experiment Station, St. Paul, MN, pp 78-79

Wang Q, Qi J, Cui X, Li W (2018) Application of improved genetic algorithm in clonal deployment for seed orchard. Sci Silv Sin 54:30-37 (in Chinese)

Wang T, Aitken SN, Woods JH, Polsson K, Magnussen S (2004) Effects of inbreeding on coastal Douglas fir growth and yield in operational plantations: a model-based approach. Theor Appl Genet 108:1162-1171

Williams CG, Savolainen O (1996) Inbreeding depression in conifers: implications for breeding strategy. For Sci 42:102-117

Woods J, Heaman J (1989) Effect of different inbreeding levels on filled seed production in Douglas-fir. Can J For Res 19:54-59

Woods JH, Wang T, Aitken SN (2002) Effects of inbreeding on coastal Douglas-fir: nursery performance. Silv Genet 51:163-170
Wu Z, Zhang Z, Wang J (2019) Estimating the productive potential of five natural forest types in northeastern China. For Ecosyst 6:42. https://doi.org/10.1186/ s40663-019-0204-0

Ye NF (1986) Analysis of possibility on the forests of Scotch pine (Pinus sylvestris var. .mongolica) on sand in the west part of Heilongjiang province. J Northeast For Univ 1:87-91 (in Chinese)

Yuan H, Niu S, El-Kassaby YA, Li Y, Li W (2016) Simple genetic distance-optimized field deployments for clonal seed orchards based on microsatellite markers: as a case of Chinese pine seed orchard. PLoS One 11:e0157646. https://doi. org/10.1371/journal.pone.0157646

Zhang G, Hui G, Hu Y, Zhao Z, Guan X, von Gadow K, Zhang G (2019) Designing near-natural planting patterns for plantation forests in China. For Ecosyst 6 ; 28. https://doi.org/10.1186/s40663-019-0187-x

Zhang LM, Fang XY, Meng YX (2012) Investigation and analysis on the planting and development of camphor pine in Yulin desert area. Yulin Sci Technol 3: 50-58 (in Chinese)

Zhao Q, Zeng DH, Lee DK, He XY, Fan ZP, Jin YH (2007) Effects of Pinus sylvestris var. mongolica afforestation on soil phosphorus status of the Keerqin Sandy lands in China. J Arid Environ 69:569-582

Zhu J, Kang H, Tan H, Xu M (2006) Effects of drought stresses induced by polyethylene glycol on germination of Pinus sylvestris var. mongolica seeds from natural and plantation forests on sandy land. J For Res 11:319-328

\section{Submit your manuscript to a SpringerOpen ${ }^{\circ}$ journal and benefit from:}

- Convenient online submission

- Rigorous peer review

- Open access: articles freely available online

- High visibility within the field

- Retaining the copyright to your article

Submit your next manuscript at $\boldsymbol{\nabla}$ springeropen.com 